\title{
Electrical Discharge Machining (EDM): A Review
}

\author{
Asfana Banu and Mohammad Yeakub Ali
}

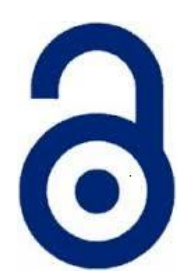

Received: 16 July 2016

Accepted: 31 July 2016

Published: 05 September 2016

Publisher: Deer Hill Publications

(C) 2016 The Author(s)

Creative Commons: CC BY 4.0

\begin{abstract}
Electro discharge machining (EDM) process is a non-conventional and non-contact machining operation which is used in industry for high precision products. EDM is known for machining hard and brittle conductive materials since it can melt any electrically conductive material regardless of its hardness. The workpiece machined by EDM depends on thermal conductivity, electrical resistivity, and melting points of the materials. The tool and the workpiece are adequately both immersed in a dielectric medium, such as, kerosene, deionised water or any other suitable fluid. This paper provides an important review on different types of EDM operations. A brief discussion is also done on the machining responses and mathematical modelling.
\end{abstract}

Keywords. WEDM, Micro-EDM, Non-conductive ceramics, dry EDM, dry WEDM, MRR, Kerf

\section{INTRODUCTION}

Electro discharge machining (EDM) process is a non-conventional and non-contact machining operation which is used in industry for high precision products especially in manufacturing industries, aerospace and automotive industries, communication and biotechnology industries [1-7]. EDM as shown in Figure 1, is known for machining hard and brittle conductive materials since it can melt any electrically conductive material regardless of its hardness [4-5]. EDM is a type of thermal machining where the material from the workpiece is removed by the thermal energy created by the electrical spark $[5,8,9]$. The workpiece machined by EDM depends on thermal conductivity, electrical resistivity, and melting points of the materials [10-12]. A series of electrical sparks or discharges occur rapidly in a short span of time within a constant spark gap between micro sized tool electrode and workpiece material. The nature of sparks is repetitive and discrete. The tool and the workpiece are adequately both immersed in a dielectric medium, such as, kerosene, deionised water or any other suitable fluid $[5,13,14]$. The non-contact nature of the process with nearly force free machining allows a soft and easy to machine electrode materials to machine a very hard, fragile or thin workpieces [15-17]. Thus, due to its non-contact nature; mechanical stresses, chatter, and vibration problems during machining can be eliminated [18]. This paper is reviewed comprehensively on types of EDM operation. A brief discussion is also done on the machining responses and mathematical modelling.

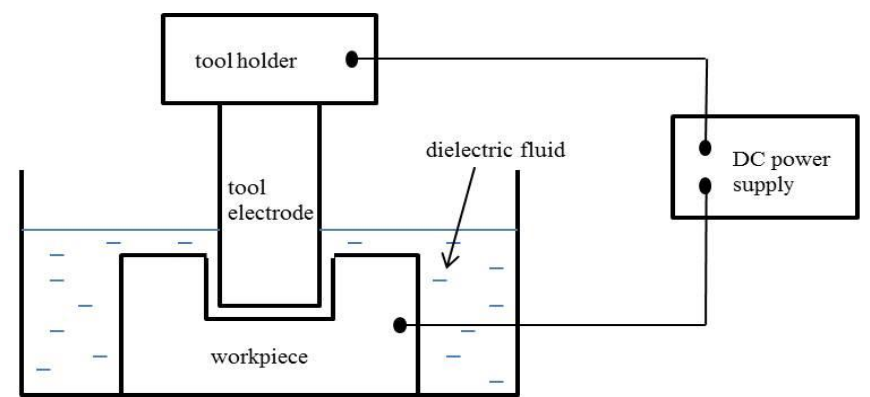

Figure 1: Schematic diagram of EDM.

\author{
A. Banu and M. Y. Ali 四 \\ Department of Manufacturing and Materials Engineering \\ International Islamic University Malaysia \\ PO Box 10, 50728 Kuala Lumpur, Malaysia \\ E-mail: mmyali@iium.edu.my
}

Reference: Banu, A. and Ali, M. Y. (2016). Electrical Discharge Machining: A Review. International Journal of Engineering Materials and Manufacture, 1(1), 3-10. 


\section{TYPES OF ELECTRO DISCHARGE MACHINING (EDM)}

Some of the variations of EDM process that can be altered for micro fabrication applications are micro-EDM, wire EDM (WEDM), dry EDM [4, 19-21]

\subsection{Wire EDM (WEDM)}

Wire electrical discharge machining (WEDM) was introduced because it has the ability to cut intricate shapes and extremely tapered geometries with high performance especially in precision, efficiency, and stability [5, 22, 23]. WEDM operation has a very similar material removal mechanism as EDM process except WEDM uses winding wire as an electrode $[5,6,24]$. Micro-WEDM operation uses a very small diameter wire $(\varnothing 20-50 \mu \mathrm{m})$ as the electrode to cut a narrow width of cut in the workpiece. The wire is pulled through the workpiece from a supply spool onto a take-up mechanism. Discharge occurs between the wire electrode and the workpiece in the presence of a flood of dielectric fluid. The most important control parameters for this process are discharge current, discharge capacitance, pulse duration, pulse frequency, wire speed, wire tension, voltage, and dielectric flushing condition [6, 20, 25].

\subsection{Micro-EDM}

EDM operation has already been developed in micro scale industries, as delicate micro tools can machine workpiece surface without any deviation or breakage. Micro-EDM follows the similar principle of conventional EDM technology. However, there are some differences between these two machining in terms of circuitry. EDM uses resistance capacitance relaxation (RC-relaxation) circuit while micro-EDM uses RC-pulse circuit. In RC-relaxation circuit, current and voltage are usually assumed as constant in modelling process. However, in reality, for RCrelaxation circuit, current and voltage are controlled at a predefined level throughout the pulse on-time. In contrast, based on the modelling process and parametric analysis, RC-pulse generator for a single discharge shows that the current and voltage are not maintained to any predefined level. Still, the RC-pulse generator depends on capacitor charge state at any instant. The RC-pulse circuit type is known to have low material removal rate (MRR) since it can produce very small amount of discharge energy. Micro-EDM is particularly developed to manufacture component of sized between 1 and $999 \mu \mathrm{m}$. Hence, in order to produce high precision and high accuracy micro geometries products, micro-EDM is a suitable type of machining [26-29].

\subsection{EDM of Non-Conductive Materials}

Materials that are able to provide a minimum electrical conductivity of $0.1 \mathrm{Scm}^{-1}$ can be processed using EDM. Thus, materials like metals and conductive ceramics are capable to undergo this process [30-32]. Researchers are applying EDM and micro-EDM to machine ceramics since they are difficult to machine using conventional cutting techniques $[33,34]$. But, in order to make the machining process to be continuous, the ceramics need to be conductive. So, one of the solutions is to create a composite with dopants such as titanium nitride (TiN) or tungsten carbide (WC) onto the ceramic. Other alternative is to create a conductive compound by embedding the ceramic particles in a metal matrix. Another approach is by using the ultrasonic assisted spark erosion. The ultrasonic energy can assist in creating spark erosion and lead to crack formation that causes spalling [10, 31, 32]. Non-conductive ceramics also have been successfully machined by EDM using the assisting electrode method (AEM) (Figure 2) with some modifications done in the process which is one of the commonly method used [31, 32, 35-37]. In AEM, a conductive layer is applied on top of the non-conductive ceramic in order to generate spark between the workpiece and the tool electrode. High temperature around the dielectric fluid will degenerate the polymer chains and creates carbon elements from cracked polymer chains. The carbon elements, together with the conductive debris cover the ceramic surface to sustain the conductivity [10, 31, 32, 36, 38-40].

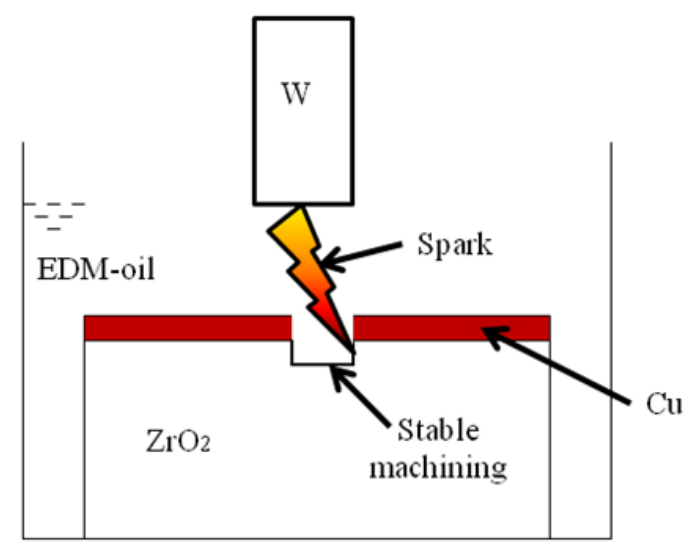

Figure 2: Schematic diagram of micro-EDM of non-conductive zirconia using adhesive copper assisting electrode [38]. 


\subsection{Dry EDM}

In EDM process, dielectric fluid plays an important role in order to flush away the debris from the machining gap. In addition, the dielectric fluid also helps to improve the efficiency of the machining operation as well as improving the quality and economy of the machined parts. The commonly used dielectric fluids are mineral oil-based liquid or hydrocarbon oils which cause fire hazard and environmental problems. This is because dielectric wastes generated during the machining operation are very toxic and non-recyclable. Besides that, during the machining operation, toxic fumes $\left(\mathrm{CO}\right.$ and $\left.\mathrm{CH}_{4}\right)$ are produced because of the high temperature chemical breakdown of mineral oils. The toxic fumes also pose a health hazard to the machining operators [24, 41-45]. In order to avoid these problems, researchers introduce dry EDM which includes dry WEDM, dry micro-EDM, and dry micro-WEDM [4, 5, 24, 46, 47].

Dry EDM (Figure 3) is a green machining method where the electrode used is in a pipe form and gas or air flows through the pipe instead of the liquid as a dielectric fluid which removes the debris from the gap and cools the machining surface [48-52]. As for dry WEDM, also known as the WEDM using dry dielectric fluid is a modification of the oil WEDM operation where gas is used as dielectric fluid instead of liquid. The flow of gas with high pressure helps to remove the debris and also avoids unnecessary heating of the wire and workpiece at the discharge gap. Lower tool wear, better surface quality, lower residual stresses, thinner white layer, and higher precision in machining are the prime outcome of this dry technique [1, 24, 53-56]. This dry technique can be applicable for almost all micro level machining operation $[52,57]$.

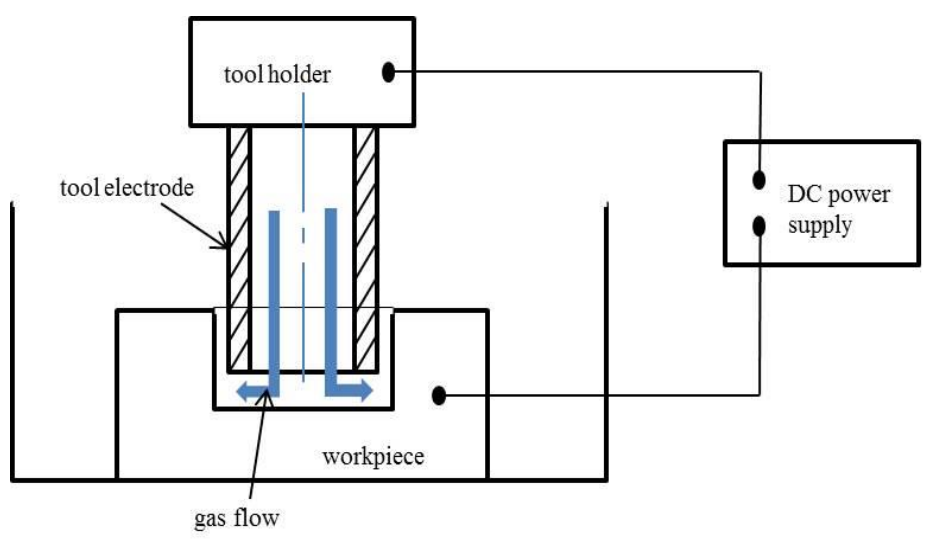

Figure 3: Schematic diagram of dry EDM.

There are researchers who do not agreed with the idea of using the gas instead of the liquid as the dielectric fluid. It is because when the sparks happened in the air, the erosion effect would be very small since the electrical discharge loses its energy. Moreover, the bubble of vapour expands which resulted from the spark into the dielectric fluid and causes the dynamic plasma pressure to rise. It is due to the surrounding dielectric fluid restricts the plasma growth. The bubble collapses and removes the molten metal out of the crater when the temperature decreases during the off time. Even though there are some disagreements among the researchers, the dry EDM was first introduced and reported by NASA in 1985 [58]. The commonly used gases as the dielectric fluid are atmospheric air, compressed air, liquid nitrogen, oxygen, argon and helium gas [51, 56, 59]. Some research shows that material removal rate (MRR) improves when oxygen is used as the dielectric fluid [60,61]. It is because the oxidation reaction occurs with the supply of the oxygen gas which increases the work removal volume during one discharge cycle. In addition, there is no corrosion on the machining surface but it may suffer from rusting due to the oxidation [61].

Compared to conventional WEDM, the vibration of the wire electrode, narrower gap distance, and very negligible process reaction force in dry micro-WEDM assists this process to enable high accuracy in finishing of cut. Higher machining speed and lower electrode wear ratio are achieved in dry EDM milling. Three dimensional (3D) machining of cemented carbide can be done by using dry EDM milling [53,62]. Higher material removal rate (MRR) can also be achieved in dry EDM when the workpiece is added with the ultrasonic vibration. This is because the ultrasonic vibration helps to flush of the molten metal from the craters [19]. Polarity is a one of the important factor in machining dry EDM. When the polarity of the tool electrode is negative, the tool wear ratio is smaller and the material removal rate is higher compared to the positive polarity $[1,56]$. The machining operation stability is maintained when the tool is in rotation or planetary motion [63]. Low electrode wear ratio in dry EDM is due to the small physical damage of the tool electrode caused by the reactive force. It is because the dry EDM is free from the vaporization of liquid dielectric fluid when the discharge occurs. Besides that, adhesion of machining debris on the electrode helps to reduce electrode wear [61]. 


\section{MACHINING RESPONSES}

\subsection{Kerf}

Kerf (Figure 4) is a width of the machined slots which is one of the most vital characteristics of WEDM [64, 65]. The corner errors and kerf variation are usually caused by the wire tool deflection and vibration in the discharge gap. These are the main factors that affect the WEDM machining accuracy. However, the kerf variations have higher influences on dimensional accuracy in micro-WEDM compared to the conventional WEDM. This is because, the relative error found in miniature parts produce by the micro-WEDM are bigger than the corresponding values in conventional WEDM [20]. Besides that, a stable machining performance in micro-WEDM is related to the debris free machined kerf. It is evident from the debris tracking analysis that the most debris are left out from the kerf section under any constant fluid flow rate. More effectively debris can be excluded and high micro-WEDM performance is obtainable with the improvement of jet flushing conditions of the working fluid from the nozzles [66].

In another study, the spark locations using the recorded images, and the effects of servo voltage, pulse interval time, and wire running speed on the distribution of spark location were investigated. The spark distribution is found uniform when servo voltage is high, pulse interval time is long, and wire running speed is low when experimental results are clarified [67]. Based on the research, the kerf on germanium wafers in micro-WEDM process was analysed using different thin wires with various voltage and capacitor settings. Up to 57\% more wafers can be sliced in microWEDM which depends on wafer thickness and the thin wires. The wafer slicing with WEDM is suggested for mainly expensive semiconductor materials [68]. A model on lateral vibration of wire is established where co-related microWEDM parameters and vibration amplitude of the wire are analysed. The wire vibration is affected by the open voltage which also measures the breakdown distance. Kerf width can be controlled and subsequently machining precision can be improved by controlling the parameter [20].

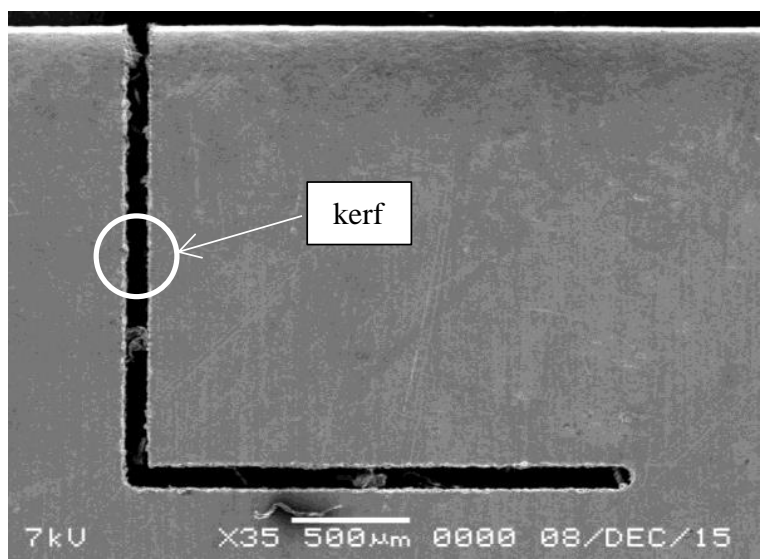

Figure 4: SEM micrograph of kerf produced by micro-WEDM with $70 \mu$ m diameter tungsten wire electrode.

\subsection{Material Removal Rate (MRR)}

Dimensional accuracy becomes vital when it comes to EDM since close tolerance components are required for products like tools, dies, and mold for press works, plastic molding, and die casting. Thus, MRR has been one of the main concerns. The MRR is expressed as the weight of material removed from workpiece over a period of machining time. Many researchers have attempted to develop empirical models to estimate MRR. The MRR depends on the amount of pulsed current in each discharge, frequency of the discharge, electrode material, work material, polarity, and dielectric flushing condition. $[12,69,70]$. MRR is low when electrode is connected to negative polarity or cathode. This is due to the dissociated carbon element in dielectric fluid tends to remain to anode and formed the recast layer [41].

Material removal mechanism in micro-EDM is debatable according to some of the researcher. This is because they are certain deviations in fundamental process mechanism. Even though they are many uncertainties regarding the mechanism of the material removal in micro-EDM, this machining process is still widely being used in industry for high-precision machining for conductive materials. Micro-EDM has the capability in removing the material in subgrain size range $(0.1-10 \mu \mathrm{m})$ regardless of their hardness [51].

\section{MATHEMATICAL MODELLING}

There are quite a numbers of studies are found on parametric study and development of empirical model on microWEDM parameters. Gap voltage, capacitance, and feed rate were considered as the control parameters and material removal rate (MRR), over cut, kerf, and surface roughness as the performance measures. The optimal parametric settings were derived using simulation. Some of the modelling are done through central composite design (CCD), response surface method (RSM), neural network method, regression analysis, neural network with back-propagation, 
neuro-fuzzy inference system (ANFIS), grey relational analysis, and Taguchi L18 orthogonal array method [20, 24, $64,71,72]$. Modelling is a strong tool for the integration of relationships between output performance and controllable input parameters. There are a few examples of mathematical modelling shown in this review. Eqn (1) is an example of mathematical model for vibration in micro end milling using Taguchi as the design while the analysis is done by the ANOVA [73]. As for Eqn (2) and (3), shows the mathematical model of hardness and MRR of nonconductive zirconia using micro-EDM [38].

$V=65.94+2.13 \times 10^{-3} \mathrm{n}-0.99 \mathrm{f}+1.73 \times 10^{-3} \mathrm{~d}-6.84 \times 10^{-5} \mathrm{nf}-1.93 \times 10^{-3} \mathrm{nd}+1.01 \mathrm{fd}$

Where; $V$ is average vibration, $\mathrm{n}$ is spindle speed $(\mathrm{rpm}), \mathrm{f}$ is feed rate $(\mathrm{mm} / \mathrm{min}), \mathrm{d}$ is depth of cut $(\mu \mathrm{m})$.

$H=9201.15-62 n+16 v+0.15 n^{2}-0.05 n v-1 \times 10^{-4} n^{3}$

Where, $\mathrm{H}=$ hardness $(\mathrm{Hv}), \mathrm{n}=$ rotational speed $(\mathrm{rpm}), \mathrm{v}=$ gap voltage $(\mathrm{V})$.

$\operatorname{MRR}=-101.7+1.9 \mathrm{n}-2.93 \mathrm{v}-4.36 \times 10^{-3} \mathrm{n}^{2}+0.012 \mathrm{v}^{2}+1.1 \times 10^{-3} \mathrm{nv}+3.1 \times 10^{-6} \mathrm{n}^{3}$

Where; MRR = material removal rate $(\mu \mathrm{g} / \mathrm{min}), \mathrm{n}=$ rotational speed $(\mathrm{rpm}), v=$ gap voltage $(\mathrm{V})$.

\section{SUMMARY}

EDM process is a flexible machining operation which has the capability in producing complex three dimensional (3D) shapes especially in manufacturing industries, aerospace and automotive industries, communication and biotechnology industries. It is known for machining hard and brittle conductive materials. The tool and the workpiece are adequately both immersed in a dielectric medium. This paper provides an important review on different types of EDM operations. A brief discussion is also done on the machining responses and mathematical modelling. This reviewed paper summarizes that:

1. WEDM has the ability to cut intricate shapes and extremely tapered geometries with high performance.

2. Micro-EDM is developed to manufacture micro geometries component with high precision and high accuracy.

3. Non-conductive ceramics machined by EDM using assisting electrode method (AEM) which leads to new structuring of advanced ceramic without geometry diversity.

4. Dry EDM is a process where gas is used as the dielectric fluid instead of the liquid. It is a process where certain modification during the machining operation is needed in order to achieve a stable machining process.

5. Machining responses such as kerf and MRR are important in order to achieve maximum material removal with high accuracy and precision components.

\section{ACKNOWLEDGEMENT}

This research was funded by Ministry of Science, Technology and Innovation, Malaysia under Research Grant SF15016-0066. The authors are grateful to those who contributed directly and indirectly in producing this paper.

\section{REFERENCES}

1. Abbas, M. N., Solomon, D. G., \& Fuad Bahari, M. (2007). A review on current research trends in electrical discharge machining (EDM). International Journal of Machine Tools and Manufacture, 47(7), 1214-1228.

2. Liao, Y. S., Chen, S. T., \& Lin, C. S. (2005). Development of a high precision tabletop versatile CNC wire-EDM for making intricate micro parts. Journal of Micromechanics and Microengineering, 15, 245-253

3. Yoo, H. K., Kwon, W. T., \& Kang, S. (2014). Development of a new electrode for micro-electrical discharge machining (EDM) using $\mathrm{Ti}(\mathrm{C}, \mathrm{N})$-based cermet. International Journal of Precion Engineering and Manufacturing, $15(4), 609-616$.

4. Hoang, K. T. \& Yang, S. H. (2013). A study on the effect of different vibration-assisted methods in micro-WEDM. Journal of Materials Processing Technology, 213, 1616-1622.

5. Hoang, K. T. \& Yang, S. H. (2015). A new approach for micro-WEDM control based on real-time estimation of material removal rate. International Journal of Precision Engineering and Manufacturing, 16 (2), 241-246.

6. Debroy, A. \& Chakraborty, S. (2013). Non-conventional optimization techniques in optimizing non-traditional machining processes: a review. Management Science Letters, 3(1), 23-38.

7. Yan, M. T. (2010). An adaptive control system with self-organizing fuzzy sliding mode control strategy for micro wire-EDM machines. International Journal of Advanced Manufacturing Technology, 50, 315-328.

8. Pour, G. T., Pour, Y. T., \& Ghoreishi, M. (2014). Electro-spark nanomachining process simulation. International Journal of Materials, Mechanics and Manufacturing, 2 (1).

9. Pour, G. T., Pour, Y. T., \& Ghoreishi, M. (2014a). Thermal model of the electro-spark nanomachining process. International Journal of Materials, Mechanics and Manufacturing, 2 (1), 56-59. 
10. Mohri, N., Fukuzawa, Y., Tani. T., Saito, N., \& Furutani, K. (1996). Assisting electrode method for machining insulating ceramics. Annals of the CIRP, 45, 201-204.

11. Mohri, N., Fukusima, Y., Fukuzawa, Y., Tani, T., \& Sato, N. (2003). Layer generation process on work-piece in electrical discharge machining. CIRP Annals - Manufacturing Technology, 52 (1), 157-160. DOI:10.1016/500078506(07)60554-X.

12. Mahardika, M., Tsujimoto, T., \& Mitsui, K. (2008). A new approach on the determination of ease of machining by EDM processes. International Journal of Machine Tools and Manufacture, 48, 746-760. DOI:10.1016/j.ijmachtools.2007.12.012.

13. Chow, H. M., Yang, L. D., Lin, C. T., \& Chen,Y. F. (2008). The use of SiC powder in water as dielectric for microslit EDM machining. Journal of Materials Processing Technology, 195 (1-3), 160-170.

14. Chen, Y. F., Lin, Y. C., Chen, S. L., \& Hsu, L. R. (2009). Optimization of electrodischarge machining parameters on $\mathrm{ZrO}_{2}$ ceramic using the Taguchi method. Proceeding of the Institution of Mechanical Engineers, Part B: Journal of Engineering Manufacture, 224, 195-205.

15. Jahan, M. P., Wong, Y. S., \& Rahman, M. (2009). A study on the quality micro-hole machining of tungsten carbide by micro-EDM process using transistor and RC-type pulse generator. Journal of Materials Processing Technology, 209, 1706-1716. DOI:10.1016/j.jmatprotec.2008.04.029.

16. Masuzawa, T. (2000). State of the art of micromachining. CIRP Annals - Manufacturing Technology, 49 (2), $473-$ 488. DOI:10.1016/S0007-8506(07)63451-9.

17. Schubert, A., Zeidler, H., Hackert, M., Schneider, J., \& Hahn, M. (2013). Enhancing micro-EDM using ultrasonic vibration and approaches for machining of nonconducting ceramics. Journal of Mechanical Engneering, 59 (3), 156-164. DOI:10.5545/sv-jme.2012.442.

18. Ho, K. H. \& Newman, S. T. (2003). State of the art electrical discharge machining (EDM). International Journal of Machine Tools and Manufacture, 43, 1287-1300. DOI:10.1016/S0890-6955(03)00162-7.

19. Chakraborty, S., Dey, V., \& Ghosh, S. K. (2015). A review on the use of dielectric fluids and their effects in electrical discharge machining characteristics. Precision Engineering, 40, 1-6.

20. Di, S., Chu, X., Wei, D., Wang, Z., Chi, G., \& Liu, Y. (2009). Analysis of kerf width in micro-WEDM. International Journal of Machine Tools and Manufacture, 49(10), 788-792.

21. Ali, M. Y., Karim, A. N. M, Adesta, E. Y. T., Ismail, A. F., Abdullah, A. A., \& Idris, M. N. (2010). Comparative study of conventional and micro WEDM based on machining of meso/micro sized spur gear. International Journal of Precision Engineering and Manufacturing, 11 (5), 779-784.

22. Chen, Z., Huang, Y., Huang, H., Zhang, Z., \& Zhang, G. (2015). Three-dimensional characteristics analysis of the wire-tool vibration considering spatial temperature field and electromagnetic field in WEDM. International Journal of Machine Tools and Manufacture, 92, 85-96.

23. Patil, P. A. \& Waghmare, C. A. (2014). A review on advances in wire electrical discharge machining. In Proceedings of the International Conference on Research and Innovation in Mechanical Engineering (pp. 179-189). Springer India.

24. Azhiri, R. B., Teimouri, R., Baboly, M. G., \& Laseman, Z. (2014). Application of Taguchi, ANFIS and grey relational analysis for studying, modelling and optimization of wire EDM process while using gaseous media. International Journal of Advanced Manufacturing Technology, 71 (1), 279-295.

25. Tosun, N. \& Cogun, C. (2003). An investigation on wire wear in WEDM. Journal of Materials Processing Technology, 134, 273-278.

26. Schubert, A., Ziedler, H., Wolf, N., \& Hackert, M. (2011). Micro electro discharge machining of electrically nonconductive ceramics. AIP Conference Proceedings, 1353, (1) 1303-1308.

27. Dhanik, S. \& Joshi, S. S. (2005). Modelling of a single resistance capacitance pulse discharge in micro-electro discharge machining. Journal of Manufacturing Science and Engineering, 127 (4), 759-767.

28. Das, S. \& Joshi, S. S. (2010). Modeling of spark erosion rate in microwire-EDM. International Journal of Advanced Manufacturing Technology, 48 (5-8), 581-596.

29. Pecas, P. \& Henriques, E. (2008). Electrical discharge machining using simple and powder-mixed dielectric: the effect of the electrode area in the surface roughness and topography. Journal of Materials Processing Technology, 200, 250-258.

30. Asfana, A., Ali, M. Y., Mohamed, A. R., \& Hung, W. N. P. (2015). Material removal rate of zirconia in electro discharge micromachining. Advanced Materials Research, 1115, 20-23.

31. Hosel, T., Cvancara, T., Ganz,T., Muller, C., \& Reinecke, H. (2011). Characterization of high aspect ratio nonconductive ceramic microstructures made by spark erosion. Microsystem Technologies, 17, 313-318.

32. Hosel, T., Muller, C., \& Reinecke, H. (2011a). Spark erosive structuring of electrically nonconductive zirconia with an assisting electrode. CIRP Journal of Manufacturing Science and Technology, 4, 357-361.

33. Schubert, A. \& Zeidler, H. (2009). Machining of nonconductive $\mathrm{ZrO}_{2}$ ceramics with micro-EDM. In: Van Brussel, H.; Brinksmeier, E.; Spaan, H. (ed): Proceedings of the $9^{\text {th }}$ International Conference of the European Society for Precision Engineering and Nanotechnology, ISBN: 978-0-9553082-6-0, S. 6-9 (Bd.2).

34. Muttamara, A., Janmanee, P., \& Fukuzawa, Y. (2010). A Study of Micro-EDM on Silicon Nitride Using Electrode Materials. International Transaction Journal of Engineering, Management, \& Applied Science \& Technologies, 1 (1), 001-007. 
35. Mohamed, A. R., Asfana, B., \& Ali, M. Y. (2014). Investigation of recast layer of non-conductive ceramic due to micro-EDM. Advanced Materials Research, 845, 857-861.

36. Muttamara, A., Fukuzawa, Y., Mohri, N., \& Tani, T. (2009). Effect of electrode material on electrical discharge machining of alumina. Journal of Materials Processing Technology, 209, 2545-2552.

37. Chen, Y. F., Lin, Y. C., Chen, S. L., \& Hsu, L. R. (2009). Optimization of electrodischarge machining parameters on $\mathrm{ZrO}_{2}$ ceramic using the Taguchi method. Journal of Engineering Manufacture, 224, 195-205.

38. Banu, A., Ali, M. Y., \& Rahman, M. A. (2014). Micro-electro discharge machining of non-conductive zirconia ceramic: investigation of MRR and recast layer hardness. International Journal of Advanced Manufacturing Technology, 75, 257-267.

39. Liu, Y. H., Li, X. P., Ji, R. J., Yu, L. L., Zhang, H. F., \& Li, Q. Y. (2008). Effect of technological parameter on the process performance for electric discharge milling of insulating $\mathrm{Al}_{2} \mathrm{O}_{3}$ ceramic. Journal of Materials Processing Technology, 208, 245-250.

40. Fukuzawa, Y., Mohri, N., Tani, T., \& Muttamara, A. (2004). Electrical discharge machining properties of noble crystals. Journal of Materials Processing Technology, 149, 393-397.

41. Pandey, A. \& Singh, S. (2010). Current research trends in variants of electrical discharge machining: a review. International Journal of Engineering Science and Technology, 2 (6), 2172-2191.

42. Kunieda, M. \& Furudate, C. (2001). High precision finish cutting by dry WEDM. CIRP Annals - Manufacturing Technology, 50 (1), 121-124.

43. Pradeep, G. M. \& Dani, M. S. H. (2015). A review on the use of pollution free dielectric fluids in wire electrical discharge machining process. Journal of Chemical and Pharmaceutical Sciences, (7), 312-315.

44. Dhakar, K \& Dvivedi, A. (2016). Parametric evaluation on near-dry electric discharge machining. Materials and Manufacturing Processes, 31, 413-421.

45. Zhang, Q. H., Zhang, J. H., Ren, S. F., Deng, J. X., \& Ai, X. (2004). Study on technology of ultrasonic vibration aided electrical discharge machining in gas. Journal of Materials Processing Technology, 149, 640-644.

46. Khatri, B. C., Rathod, P., \& Valaki, J. B. (2015). Ultrasonic vibration-assisted electric discharge machining: a research review. Proceedings of the Institution of Mechanical Engineers, Part B: Journal of Engineering Manufacture, 1-12. DOI: 10.1177/0954405415573061.

47. Wang, T., Xie, S. Q., Xu, X. C., Chen, Q., Lu, X. C., \& Zhou, S. H. (2012). Application of uniform design in experiments of WEDM in gas. Advanced Materials Research, 426, 11-14.

48. Mahendran, S. \& Ramasamy, D. (2010). Micro-EDM: overview and recent developments. In National Conference in Mechanical Engineering Research and Postgraduate Students (1 ${ }^{\text {st }}$ NCMER 2010), 26-27 May 2010, Pahang, Malaysia, 480-494.

49. Fujiki, M., Ni, J., \& Shih, A. J. (2011). Tool path planning for near-dry EDM milling with lead angle on curved surfaces. Journal of Manufacturing Science and Engineering, 133(5), 051005.

50. Besliu, I., Schulze, H. P., Coteata, M., \& Amarandei, D. (2010). Study on the dry electrical discharge machining. International Journal of Material Forming, 3(1), 1107-1110.

51. Paul, G., Roy, S., Sarkar, S., Hanumaiah, N., \& Mitra, S. (2013). Investigations on influence of process variables on crater dimensions in micro-EDM of titanium aluminide alloy in dry and oil dielectric media. International Journal of Advanced Manufacturing Technology, 65, 1009-1017.

52. Skrabalak, G. \& Kozak, J. (2010). Study on dry electrical discharge machining. Wear, 5, 7.

53. Wang, T. \& Kunieda, M. (2004). Dry WEDM for finish cut. Key Engineering Materials, 259-260, 562-566.

54. Kunieda, M., Lauwers, B., Rajurkar, K. P., \& Schumacher, B. M. (2005). Advancing EDM through fundamental insight into the process. CIRP Annals-Manufacturing Technology, 54(2), 64-87.

55. Liqing, L. \& Yingjie, S. (2013). Study of dry EDM with oxygen-mixed and cryogenic cooling approaches. Procedia CIRP, 6, 344-350.

56. Singh, P., Chaudhary, A. K., Singh, T., \& Rana, A. K. (2015). Comparison of outputs for dry EDM and EDM with oil: a review. International Journal for Research in Emerging Science and Technology, 2(6), 45-49.

57. Yu, Z. B., Takahashi, J., Nakajima, N., Sano, S., \& Kunieda, M. (2005). Feasibility of 3-D surface machining by dry EDM. International Journal of Electrical Machining, 10, 15-20.

58. Leao, F. N. \& Pashby, I. R. (2004). A review on the use of environmentally-friendly dielectric fluids in electrical discharge machining. Journal of Materials Processing Technology, 149, 341-346.

59. Besliu, I. \& Coteata, M. (2009). Characteristics of the dry electrical discharge machining. Nonconventioal Technologies, 2, 5-8.

60. Teimouri, R. \& Baseri, H. (2013). Experimental study of rotary magnetic field-assisted dry EDM with ultrasonic vibration of workpiece. International Journal of Advanced Manufacturing Technology, 67(5-8), 1371-1384.

61. Jahan, M. P., Rahman, M., \& Wong, Y. S. (2011). A review on the conventional and micro-electrodischarge machining of tungsten carbide. International Journal of Machine Tools and Manufacture, 51, 837-858.

62. Yu, Z., Jun, T., \& Masanori, K. (2004). Dry electrical discharge machining of cemented carbide. Journal of Materials Processing Technology, 149(1), 353-357.

63. Chandra, B., Singh, H., \& Garg, J. (2011). A review on emerging areas of interest in electrical discharge machining. International Journal of Advanced Engineering Technology, 2(3), 1-9. 
64. Hoang, K. T. \& Yang, S. H. (2015a). Kerf analysis and control in dry micro-wire electrical discharge machining. International Journal of Advanced Manufacturing Technology, 78, 1803-1812.

65. Ghodsiyeh, D., Golshan, A., \& Shirvanehdeh, J. A. (2013). Review on current research trends in wire electrical discharge machining (WEDM). Indian Journal of Science and Technology, 6(2), 4128-4140.

66. Okada, A., Uno, Y., Onoda, S., \& Habib, S. (2009). Computational fluid dynamics analysis of working fluid flow and debris movement in wire EDMed kerf. CIRP Annals-Manufacturing Technology, 58(1), 209-212.

67. Okada, A., Uno, Y., Nakazawa, M., \& Yamauchi, T. (2010). Evaluations of spark distribution and wire vibration in wire EDM by high-speed observation. CIRP Annals-Manufacturing Technology, 59(1), 231-234.

68. Rakwal, D. \& Bamberg, E. (2009). Slicing, cleaning and kerf analysis of germanium wafers machined by wire electrical discharge machining. Journal of Materials Processing Technology, 209(8), 3740-3751.

69. Dave, H. K., Desai, K. P., \& Raval, H. K. (2012). Modelling and analysis of material removal rate during electro discharge machining of Inconel 718 under orbital tool movement. International Journal of Manufacturing Systems, 2 (1), 12-20.

70. Somashekhar, K. P., Ramachandran, N., \& Mathew, J. (2010). Optimization of material removal rate in microEDM using artificial neural network and genetic algorithms. Materials and Manufacturing Processes, 25, 467-475.

71. Yang, R. T., Tzeng, C. J., Yang, Y. K., \& Hsieh, M. H. (2012). Optimization of wire electrical discharge machining process parameters for cutting tungsten. International Journal of Advanced Manufacturing Technology, 60(1-4), 135-147.

72. Somashekhar, K. P., Mathew, J., \& Ramachandran, N. (2012). A feasibility approach by simulated annealing on optimization of micro-wire electric discharge machining parameters. International Journal of Advanced Manufacturing Technology, 61(9-12), 1209-1213.

73. Ali, M. Y., Mohamed, A. R., Khan, A. A., Asfana, B., Lutfi, M., \& Fahmi, M. I. (2013). Empirical modelling of vibration in micro end milling of PMMA. World Applied Sciences Journal (Mathematical Applications in Engineering), 21, 73-78. 